IP $\rightleftharpoons$ B

\title{
Recipiente de fibras de Attalea funifera para produção de mudas de eucalipto
}

\author{
Andrea Vita Reis Mendonça ${ }^{1}$, Lucas Gonçalves Ribeiro, José Roque Azevedo Assunção ${ }^{1}$,Teresa Aparecida Soares de Freitas ${ }^{1 *}$, \\ Josival Santos Souza ${ }^{1}$
}

1Universidade Federal do Recôncavo da Bahia, Rua Rui Barbosa, 710, CEP 44380-000, Cruz das Almas, BA, Brasil

*Autor correspondente:

teresa@ufrb.edu.br

Termos para indexação:

Desenvolvimento de planta

Piaçava da Bahia

Viveiro florestal

Index terms:

Plant development

Piaçava da Bahia

Forest nursery

Histórico do artigo:

Recebido em 17/03/2016

Aprovado em 15/08/2016

Publicado em 30/09/2016

doi: 10.4336/2016.pfb.36.87.1186

\begin{abstract}
Resumo - O objetivo deste estudo foi avaliar a viabilidade técnica do uso de recipientes biodegradáveis, feitos de resíduos de fibras de Attalea funifera Martius, na produção de mudas de Eucalyptus camaldulensis Dehnh. O trabalho foi desenvolvido em três fases: confecção dos recipientes biodegradáveis, produção de mudas e simulação em campo. O experimento da fase de produção de mudas foi realizado em delineamento inteiramente casualizado (DIC), com dois tratamentos (tubete de polietileno e recipiente biodegradável), 10 repetições com 64 plântulas por repetição. Após 93 dias, as mudas foram avaliadas por meio de variáveis indicadoras de qualidade. $\mathrm{O}$ experimento para simular o crescimento inicial em campo consistiu no plantio de mudas em recipientes de $11 \mathrm{~L}$, realizado em DIC com três tratamentos: mudas produzidas em tubetes de polietileno; mudas produzidas em recipientes biodegradáveis, sem a remoção do recipiente durante o plantio; e mudas produzidas em recipientes biodegradáveis, com a remoção do recipiente durante o plantio, com dez repetições para cada tratamento, com uma muda por repetição. Os recipientes biodegradáveis resistiram ao ciclo de produção, resultando em mudas com padrões de qualidade aceitáveis. A utilização do recipiente biodegradável, feito de fibras de piaçava, dispensou a remoção deste no plantio definitivo.
\end{abstract}

\section{Containers of Attalea funifera fibers to produce eucalyptus seedlings}

\section{Introdução}

A produção de mudas em tubetes de polietileno, introduzidos no Brasil na década de 1980, representou um grande avanço na silvicultura, facilitando a mecanização e produção em larga escala (Freitas et al., 2009). Entretanto, a utilização deste tipo de recipiente implica na necessidade de sua remoção no ato do plantio 
e o retorno para higienização. Segundo Simões \& Silva (2010) a desinfestação de tubetes é responsável por $10,9 \%$ dos custos de produção de mudas de eucalipto. O tempo de depreciação dos tubetes é de 10 anos, com custo percentual anual de manutenção de 3\% (Dias et al., 2011).

Neste contexto, estudos têm sido realizados, buscando desenvolver recipientes para produção de mudas a base de materiais orgânicos biodegradáveis, eliminando, assim, custos relativos ao retorno e desinfecção. De Conti et al. (2012) avaliaram recipientes biodegradáveis a base de fibra de coco e bagaço de cana para produção de mudas de três espécies arbóreas, observando menor crescimento das mudas e maior custo de produção, quando comparados aos tubetes de polietileno. Menor crescimento também foi observado por Ferraz et al. (2015), avaliando tubete biodegradável de material fibroso vegetal constituído a base de fécula de mandioca e raspa de madeira em comparação com sacolas plásticas, para a produção de Petunia x hybrida. No entanto, Silva et al. (2014) verificaram a viabilidade de utilização de colmos de bambu como recipientes para cultivo de mudas de Inga vera Willd e observaram que os colmos com furos transversais para drenagem resultaram em maior crescimento vegetativo das mudas.

Uma das dificuldades no desenvolvimento de recipientes orgânicos é a resistência necessária para manter a integridade durante o ciclo de produção das mudas. Ao mesmo tempo, após o plantio em campo, é desejável que o recipiente não imponha resistência ao desenvolvimento das raízes, dispensando assim a necessidade da remoção do mesmo no momento do plantio. De Conti et al. (2012), ao avaliarem o potencial de recipientes biodegradáveis para produção de mudas de três espécies arbóreas, observaram que a resistência mecânica dos recipientes de fibra de coco e bagaço de cana foi comprometida após 45 dias, não completando o ciclo de produção.

A fibra vegetal da piaçava da Bahia é extraída da palmeira Attalea funifera Martius, espécie endêmica da Mata Atlântica. De acordo com D'Almeida et al. (2006), esta fibra é utilizada na fabricação de vassouras, escovas, cordas, cestas, tapetes e telhados. A piaçava gerou para o Brasil uma receita de $\mathrm{R} \$ 82,9$ milhões em 2013, correspondente a 44.617 t, sendo a Bahia responsável por $95,2 \%$ da produção nacional (IBGE, 2013). Parte destas fibras é descartada pelas indústrias de transformação, como refugo ou fibras fora do padrão.
Segundo D'Almeida et al. (2006), o refugo gerado chega a 20\%. Savastano Júnior et al. (1997) relataram, com base em dados da cidade de Valença, BA, que o refugo da fibra limpa e penteada está em torno de 30\% (1.000 t por ano) e não tem nenhum aproveitamento, enquanto as fibras fora dos padrões correspondem de 10 a $15 \%$ (12 t) e tem aproveitamento parcial.

O objetivo deste trabalho foi avaliar a viabilidade técnica do uso de recipientes biodegradáveis, constituídos de resíduo de fibra de piaçava, na produção de mudas de Eucalyptus camaldulensis Dehnh.

\section{Material e métodos}

O experimento iniciou-se em 2012, sendo dividido em três etapas: confecção dos recipientes orgânicos, produção de mudas e simulação em campo. As duas primeiras etapas foram realizadas no município de Nilo Peçanha, BA, cidade pertencente à região da Costa

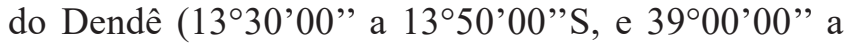
39॰30'00"W). O clima é Tropical sem Estação Seca (AF), precipitação média anual de 1.600 a $1.900 \mathrm{~mm}$ e temperatura média de 24 a $26{ }^{\circ} \mathrm{C}$ (Alvarez et al., 2013).

A terceira etapa, denominada simulação em campo, foi realizada no viveiro localizado em Cruz das Almas, BA, situado a $12^{\circ} 40^{\prime} 12^{\prime \prime} \mathrm{S}$ e $39^{\circ} 06^{\prime} 07^{\prime \prime} \mathrm{W}$. O clima é Tropical com Verão Seco (AS), precipitação média anual de 1.300 a $1.600 \mathrm{~mm}$ e temperatura média anual de 24 a $26^{\circ} \mathrm{C}$ (Alvarez et al., 2013).

\section{Desenvolvimento do recipiente biodegradável}

A matéria prima para fabricação dos recipientes biodegradáveis foi fornecida pela Cooperativa das Produtoras e Produtos Rurais da Área de Preservação Ambiental de Pratigi (COOPRAP), localizada em Nilo Peçanha, BA. Este material é o resíduo proveniente da produção de vassouras, composto por cascas de fibras, fibras curtas e finas.

Os recipientes a serem confeccionados deveriam ter volume e forma semelhante aos tubetes de polietileno de $54 \mathrm{~cm}^{3}$, utilizados como controle. Assim, inicialmente foram confeccionadas formas de cimento para moldar os recipientes, utilizando os tubetes comerciais de polietileno $\left(54 \mathrm{~cm}^{3}\right)$ como moldes. A confecção foi realizada de forma artesanal. O resíduo foi misturado à água e à fécula de mandioca, em aquecimento de $100^{\circ} \mathrm{C}$, e o composto resultante foi moldado nas formas de cimento. Antes de receberem a mistura, os moldes foram envolvidos em plástico cobertos por óleo vegetal 
residual de frituras. Após aderir a massa ao molde, a mesma foi envolvida por palha-da-costa, outro resíduo da piaçava semelhante à palha, para melhor fixação. $\mathrm{Na}$ sequência, os recipientes aderidos aos moldes foram secos ao ar livre, em ambiente com cobertura, por um período de cinco dias. Após secagem, a palha foi removida e os recipientes estavam prontos para utilização. As etapas da confecção dos recipientes estão ilustradas na Figura 1.
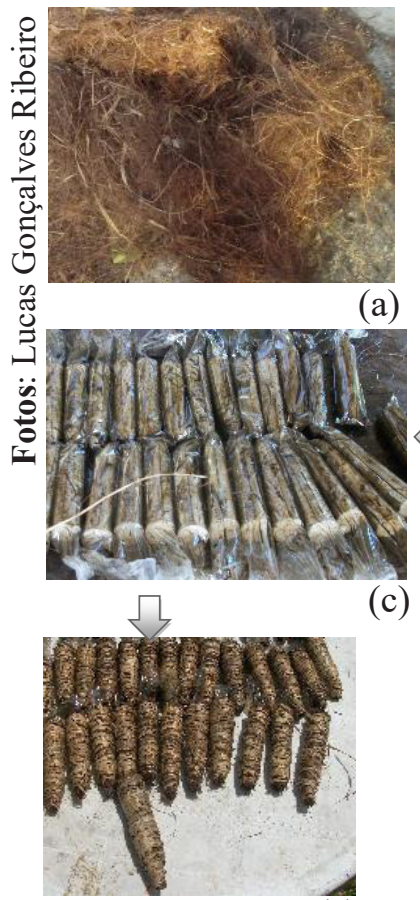

(c)

(e)
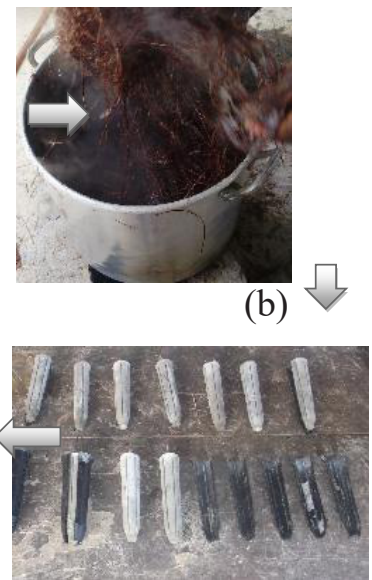

(d)

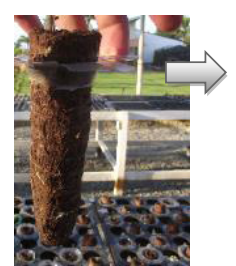

(f)
Figura 1. Etapas da confecção dos recipientes orgânicos: a) cascas de fibras, e fibras curtas e finas; b) cozimento das fibras; c) confecção dos moldes; d) moldes envoltos por sacos plásticos untados com óleo; e) composto de fibras aderidos aos moldes e envolvidos com palha da costa para secagem; f) recipiente pronto para utilização.

Para confecção de 100 recipientes biodegradáveis utilizaram-se, em média, $2,3 \mathrm{~kg}$ do resíduo de piaçava, 1,3 $\mathrm{kg}$ de fécula de mandioca, 7,7 L de água, com tempo médio de cozimento da massa de $40 \mathrm{~min}$.

\section{Produção de mudas}

Para avaliar a viabilidade técnica do uso de recipientes biodegradáveis de piaçava na produção de mudas de eucalipto foi realizado um experimento, no período de setembro a dezembro de 2012, em delineamento inteiramente casualizado, com dois tratamentos: tubetes de polietileno de $54 \mathrm{~cm}^{3}$ e recipientes biodegradáveis de resíduos de piaçava de volume aproximado de
$54 \mathrm{~cm}^{3}$, com dez repetições de 64 mudas por repetição. As mudas foram produzidas em bancadas suspensas, em estufa a $30 \%$ de sombreamento, sendo os tubetes e recipientes biodegradáveis sustentados por bandejas de polietileno. Para fixar os recipientes biodegradáveis nas bandejas foi necessário adaptar um suporte a este recipiente, confeccionado com material proveniente de garrafa de refrigerante (Figura 2).

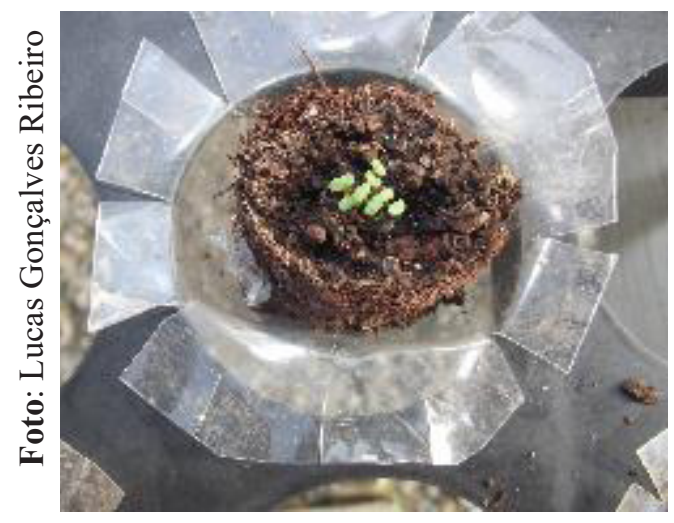

Figura 2. Suporte para fixar recipientes orgânicos nas bandejas.

A espécie utilizada foi o E. camaldulensis, devido ao amplo conhecimento sobre produção de mudas de espécies deste gênero, sendo as sementes provenientes do Instituto de Pesquisa e Estudos Florestais (IPEF), safra 2007.

Os recipientes de fibra de piaçava e os tubetes de polietileno foram preenchidos com substrato comercial para espécies florestais (Plantmax Florestal), suplementado com adubo de liberação lenta, osmocote (19-6-10), na dose de $1,5 \mathrm{~kg} \mathrm{~m}^{-3}$ de substrato. O semeio foi realizado de forma manual. A irrigação foi realizada duas vezes ao dia (as $8 \mathrm{~h}$ e as $17 \mathrm{~h}$ ), até o ponto de saturação do substrato. Quando as plântulas apresentaram um par de folhas, aos 30 dias após a semeadura, foi realizado o raleio, mantendo-se apenas a plântula mais vigorosa e central por tubete ou recipiente.

Aos 93 dias, as mudas foram avaliadas quanto ao diâmetro do coleto e altura da parte aérea, sendo, selecionadas aleatoriamente duas mudas de cada repetição e seccionadas em parte aérea e raiz. As raízes foram lavadas com água corrente, com auxílio de peneiras para minimizar perdas de raízes finas. Em seguida, mensurou-se o comprimento da raiz principal, o número de raízes primárias e secundarias e o número de deformações (dobramento, enovelamento ou 
estrangulamento) ocorrentes nestas raízes, conforme Freitas et al. (2009). Na sequência, o sistema radicular e a parte aérea de cada muda foram submetidos à secagem em estufa, a $75^{\circ} \mathrm{C}$ por $72 \mathrm{~h}$, e pesagem em balança de precisão $(0,001 \mathrm{~g})$.

As folhas de cada muda foram destacadas e dispostas sem sobreposição em aparelho scanner, obtendo-se a imagem digitalizada e a área foliar foi contabilizada no software ImageJ (National Institutes of Health, 2015).

Calculou-se a razão comprimento da parte aérea pelo comprimento do sistema radicular; razão massa seca da parte aérea pela massa seca do sistema radicular; razão da altura pelo diâmetro do coleto, também denominado de quociente de robustez; porcentagem da massa seca do sistema radicular em relação à massa seca total; porcentagem de deformação de raízes, obtida pelo número total de raízes primárias e secundárias dividido pelo número total de deformações; e foi calculado o índice de qualidade Dickson (Dickson et al., 1960).

Durante o ciclo de produção das mudas, os recipientes biodegradáveis foram diariamente avaliados quanto à integridade, sendo classificados de acordo com as seguintes categorias: sem deformações, parcialmente deformados e totalmente deformados.

Os dados foram testados quanto à normalidade dos resíduos (Teste de Shapiro-Wilk) e submetidos a análises de variância $(\alpha=0,05)$, Programa $R$ version 3.1.3 ( $R$ Development Core Team, 2015).

\section{Simulação em campo}

O experimento de simulação em campo foi desenvolvido em ambiente aberto, no período de dezembro de 2012 a março de 2013. O delineamento experimental foi inteiramente casualizado, com três tratamentos: mudas produzidas em tubetes de polietileno; mudas produzidas em recipientes biodegradáveis, sem remoção do recipiente no ato do plantio; e mudas produzidas em recipientes biodegradáveis, com remoção do recipiente no ato do plantio. Foram utilizadas dez repetições por tratamento, com uma muda por repetição.

Foram utilizadas mudas com 95 dias, provenientes do experimento de produção de mudas. Essas foram plantadas em sacolas de $11 \mathrm{~L}$, preenchidas com terra de subsolo adubado com N-P-K (04-14-08), na proporção de $3 \mathrm{Kg}$ de adubo para cada $500 \mathrm{~L}$ de solo. Na ausência de chuva, a irrigação foi realizada duas vezes ao dia, buscando manter saturação do substrato em torno de $60 \%$.
Aos 120 dias, todas as mudas foram avaliadas quanto à altura da parte aérea, diâmetro ao nível do solo, número de raízes (secundárias e terciárias), percentagem de deformação de raízes em relação ao número de raízes produzidas, comprimento de raízes laterais até a profundidade de $5 \mathrm{~cm}$ e massa seca de raízes e parte aérea. Na sequência, as mudas foram separadas, lavadas e pesadas, conforme descrito anteriormente para as mudas aos 93 dias após o plantio.

Para avaliações relativas ao comprimento de raízes laterais, foi retirada uma amostra de solo distanciada a $5 \mathrm{~cm}$ do caule de cada planta, utilizando-se um cilindro de metal, com $5 \mathrm{~cm}$ de diâmetro e de altura. Estas amostras foram lavadas em peneiras de malhas finas (abertura de 1,7 mm) e as raízes separadas e montadas em scanner para obtenção de imagem digitalizada, mensurando-se, posteriormente, o comprimento de raízes laterais, por meio do Software Safira (Embrapa Instrumentação Agropecuária, 2015). Os resultados foram apresentados $\mathrm{em} \mathrm{m} \mathrm{dm}^{-3}$.

Os dados foram testados quanto à normalidade dos resíduos (Teste de Shapiro-Wilk) e submetidos a análises de variância e teste de médias Scott-Knott $(\alpha=0,05)(R$ Development Core Team, 2015).

\section{Resultados e discussão}

$\mathrm{Na}$ avaliação da integridade dos recipientes biodegradáveis de resíduo de piaçava foi observado que $100 \%$ se mantiveram sem deformações durante todo o período de produção das mudas de eucalipto (93 dias). Este resultado evidencia o potencial do recipiente de piaçava para produção de mudas, considerando que um dos principais desafios no desenvolvimento deste tipo de recipiente é a manutenção da integridade até a obtenção de mudas com qualidade para plantio em campo. De Conti et al. (2012), ao testarem recipientes à base de fibra de coco e bagaço de cana, não obtiveram resultados promissores, sendo que aos 45 dias após o semeio, a resistência mecânica destes recipientes foi comprometida, em decorrência da elevada absorção de água, o que prejudicou a aderência de suas fibras e favoreceu o estabelecimento de fungos e a aceleração da decomposição, resultando no rompimento dos recipientes.

Além da manutenção da estrutura física, o recipiente propiciou o crescimento adequado das mudas, o que pode 
ser avaliado com base nas características morfológicas utilizadas como indicadoras de qualidade de mudas. Quanto à altura, apenas o recipiente orgânico resultou em mudas dentro dos padrões de qualidade recomendados para esta espécie, que de acordo com Ngulube (1988) deve estar entre 16 a $25 \mathrm{~cm}$. As mudas produzidas nos tubetes de polietileno atingiram alturas maiores que aquelas obtidas nos recipientes orgânicos (Tabela 1).

Tabela 1. Médias de altura da parte aérea e diâmetro ao nível do colo em mudas de Eucalyptus camaldulensis Dehnh, aos 93 dias após a semeadura, produzidas em dois tipos de recipientes.

\begin{tabular}{lcc}
\hline & Altura (cm) & Diâmentro (mm) \\
\hline Tubete de polietileno & $29,05 \mathrm{a}$ & $2,11 \mathrm{a}$ \\
Recipiente Orgânico & $22,87 \mathrm{~b}$ & $1,92 \mathrm{~b}$ \\
CV\% & 3,5 & 3,9 \\
F calculado & 148,8 & 17,37 \\
NS & $1,622 * 10-9$ & 0,000645 \\
\hline
\end{tabular}

Médias seguidas por letras iguais nas colunas não diferem estatisticamente pelo teste F/ANOVA. NS - nível de significância; CV\% - coeficiente de variação; Fcal - F calculado

No tubete de polietileno, o diâmetro do colo foi maior em relação ao recipiente orgânico, e alcançou valor mínimo indicado para mudas de eucalipto (> $2 \mathrm{~mm}$ ), conforme Wendling \& Dutra (2010). De Conti et al. (2012) afirmaram que uma das causas do pior desempenho das mudas produzidas em recipientes a base de fibra de coco e bagaço de cana foi a maior propensão destes recipientes à perda de água. Portanto, uma possível explicação para o menor crescimento das mudas do recipiente orgânico em relação ao diâmetro do colo é que a maior porosidade deste recipiente pode ter favorecido a perda de água, prejudicando o crescimento da muda, problema que pode ser contornado com manejo da irrigação e utilização de substratos, com características físicas que minimizem a perda de água.
Em vários estudos de produção de mudas com diferentes espécies de eucalipto, as plantas não têm alcançado o valor de diâmetro mínimo de $2 \mathrm{~mm}$ ao final do ciclo de produção, mesmo para os tratamentos de melhor desempenho, como exemplo: Petter et al. (2012) com Eucalyptus urophylla S. T. Blake; Kratz \& Wendling (2013), com E. dunnii Maiden e Kratz et al. (2013), com E. benthamii Maiden \& Cambage, evidenciando que este valor de referência genérico pode não se aplicar a todas as espécies do gênero Eucalyptus.

As variáveis, massa seca do sistema radicular (MSR), percentagem de deformação de raízes, (\% D), percentagem da massa seca do sistema radicular em relação à massa seca total (\% MSR), razão altura $(\mathrm{cm})$ por diâmetro do colo $(\mathrm{mm})(\mathrm{H} / \mathrm{D})$, razão do comprimento da parte aérea pelo comprimento da raiz (PA/R), razão massa seca aérea por massa seca de raízes (MSPA/MSR), comprimento da raiz principal (CRP) e índice de qualidade de Dickson (IQD) das mudas produzidas variaram em função dos recipientes (Tabela 2). Os valores de área foliar, massa seca da parte aérea, massa seca total e número de raízes das mudas não diferiu em função dos recipientes testados, sugerindo a potencialidade de utilização dos recipientes à base de piaçava para produção de mudas.

De acordo com Gomes \& Paiva (2011) quanto mais abundante o sistema radicular, maior a chance de sobrevivência da muda em campo, independente da altura da parte aérea, sendo a massa seca de raízes um importante indicador de qualidade de mudas por estar relacionada à sobrevivência e crescimento inicial em campo. Neste sentido, a maior massa seca de raízes e o maior comprimento da raiz principal das mudas produzidas em recipientes orgânicos de piaçava (Tabela 2) são evidências do potencial deste recipiente para produção de mudas. A maior produção de raízes também pode proporcionar maior estabilidade do substrato e consequentemente mudas de melhor qualidade. 
Tabela 2. Área foliar (AF), massa seca da parte aérea (MSPA), massa seca total (MST), comprimento da raiz principal (CRP) e número de raízes (NR) de mudas de Eucalyptus camaldulensis, aos 93 dias após a semeadura, produzidas em dois tipos de recipientes.

\begin{tabular}{rccccc}
\hline & $\begin{array}{c}\text { Tubete } \\
\text { polietileno }\end{array}$ & $\begin{array}{c}\text { Recipiente } \\
\text { Orgânico }\end{array}$ & CV\% & F calculado & $\begin{array}{c}\text { Nível de } \\
\text { significância }\end{array}$ \\
\hline AF $\left(\mathrm{mm}^{2}\right)$ & $108,18 \mathrm{a}$ & $95,11 \mathrm{a}$ & 25,8 & 1,19 & 0,29 \\
MSPA $(\mathrm{g})$ & $0,94 \mathrm{a}$ & $0,83 \mathrm{a}$ & 23,9 & 1,37 & 0,26 \\
$\mathrm{MST}(\mathrm{g})$ & $1,23 \mathrm{a}$ & $1,21 \mathrm{a}$ & 24,4 & 0,018 & 0,896 \\
$\mathrm{NR}$ & $8,25 \mathrm{a}$ & $9,25 \mathrm{a}$ & 32,7 & 0,61 & 0,45 \\
MSR $(\mathrm{g})$ & $0,29 \mathrm{~b}$ & $0,38 \mathrm{a}$ & 26,4 & 4,43 & 0,049 \\
$\% \mathrm{D}$ & $57,6 \mathrm{a}$ & $25,1 \mathrm{~b}$ & 52,4 & 11,24 & 0,004 \\
$\% \mathrm{MSR}$ & $23,6 \mathrm{~b}$ & $31,3 \mathrm{a}$ & 10,6 & 34,99 & $1,34 * 10^{-5}$ \\
$\mathrm{H} / \mathrm{D}$ & $13,2(2,58) \mathrm{a}$ & $10,4(2,34) \mathrm{b}$ & 3,4 & 38,78 & $7,10^{*} 10^{-6}$ \\
$\mathrm{PA} / \mathrm{R}$ & $2.60 \mathrm{a}$ & $1.89 \mathrm{~b}$ & 10,3 & 49,60 & $1,43^{*} 10^{-6}$ \\
$\mathrm{MSPA} / \mathrm{MSR}$ & $3.24 \mathrm{a}$ & $2.26 \mathrm{~b}$ & 15,1 & 31,46 & $2,53 * 10^{-5}$ \\
$\mathrm{CRP}(\mathrm{cm})$ & $13,05 \mathrm{~b}$ & $13,99 \mathrm{a}$ & 3,32 & 21,92 & 0,00019 \\
$\mathrm{IQD}$ & $0,08 \mathrm{~b}$ & $0,10 \mathrm{a}$ & 26,9 & 3,47 & 0,079 \\
\hline
\end{tabular}

Médias seguidas por letras iguais nas linhas não diferem estatisticamente pelo teste F/ANOVA. CV\% - coeficiente de variação; Fcal - F calculado.

O quociente de robustez (H/D) foi maior nas mudas dos tubetes de polietileno (Tabela 3). De acordo com Gomes \& Paiva (2011), quanto menor for o quociente de robustez maior será a sobrevivência e o estabelecimento das mudas em campo.

As paredes dos tubetes de polietileno não são perfuráveis, o que favorece a produção de mudas com deformações radiculares (Freitas et al., 2005), com a consequente redução da taxa de crescimento em campo. Estudos realizados por Figueiredo et al. (2014), em mudas clonais de eucalipto, demonstraram que deformações radiculares causam redução na taxa fotossintética e na condutividade hidráulica do sistema radicular. $\mathrm{O}$ recipiente produzido a partir do resíduo de fibra de piaçava resultou em mudas com menores deformações no sistema radicular (Tabela 2), certamente devido à maior permeabilidade de suas paredes.

O IQD é muito utilizado como indicador de qualidade de mudas, e foi maior para mudas produzidas nos recipientes orgânicos (Tabela 2). A recomendação genérica do valor mínimo de 0,2 para este índice tem sido considerada em alguns estudos (Kratz \& Wendling, 2013; Rudek et al., 2013; Nogueira et al., 2014). Nos tratamentos empregados neste trabalho, o IQD foi menor do que 0,2 (Tabela 3). Entretanto, este valor de referência foi proposto para as espécies Pseudotsuga menziesii e Picea abies (Gomes \& Paiva, 2011; Kratz \& Wendling, 2013; Nogueira et al., 2014) e, portanto, não é esperado que se aplique a todas as espécies. Em vários estudos com Eucalyptus, o valor do IQD foi menor do que 0,2, mesmo para os tratamentos de melhor desempenho (Gomes et al., 2002; Oliveira Júnior et al., 2011; Petter et al., 2012; Kratz \& Wendling, 2013; Batista et al., 2014). Para Gomes et al. (2013) o IQD pode variar em função da espécie, do manejo das mudas no viveiro, do tipo e proporção do substrato, do volume do recipiente e idade da muda. Assim, não é possível estabelecer uma recomendação geral, mas para uma mesma espécie a qualidade de mudas submetidas a diferentes tratamentos pode ser diferenciada por este índice.

O plantio da muda sem a retirada do tubete não interferiu no estabelecimento e no crescimento inicial das plantas em campo, não sendo observada diferenças entre tratamentos (Tabela 3), indicando não ser necessária a remoção do tubete orgânico no momento do plantio, o que minimiza a geração de resíduos e preserva o torrão, evitando danos ao sistema radicular. 
Tabela 3. Variáveis de parte aérea e sistema radicular de mudas de Eucalyptus camaldulensis, aos 120 dias após o plantio de simulação de campo.

\begin{tabular}{cccccccc}
\hline & H $(\mathbf{c m})$ & D $(\mathbf{m m})$ & CRL 0,5 & \% DR & NR & MSR (g) & MSPA(g) \\
\hline TP & $144,4 \mathrm{a}$ & $17,22 \mathrm{a}$ & $5,73(34,32) \mathrm{a}$ & $169,76 \mathrm{a}$ & $25,1 \mathrm{a}$ & $51,0 \mathrm{a}$ & $144,0 \mathrm{a}$ \\
PRC & $155,8 \mathrm{a}$ & $17,67 \mathrm{a}$ & $5,52(31,17) \mathrm{a}$ & $144,16 \mathrm{a}$ & $25,2 \mathrm{a}$ & $53,5 \mathrm{a}$ & $135,5 \mathrm{a}$ \\
PRS & $149,3 \mathrm{a}$ & $17,72 \mathrm{a}$ & $5,34(30,08) \mathrm{a}$ & $146,17 \mathrm{a}$ & $26,8 \mathrm{a}$ & $58,5 \mathrm{a}$ & $129,5 \mathrm{a}$ \\
\hline CV\% & 18,9 & 10,7 & 21.6 & 36,9 & 24,7 & $14,1 \mathrm{a}$ & 27,3 \\
Fcal & 0,22 & 0,41 & 0,73 & 0,63 & 0,23 & 2,45 & 0,38 \\
NS & 0,81 & 0,67 & 0,49 & 0,54 & 0,80 & 0,10 & 0,69 \\
\hline
\end{tabular}

Médias seguidas por letras iguais nas colunas não diferem estatisticamente pelo teste Scott-Knott a 5\% de probabilidade. ( ) valores entre parênteses não transformados: comprimento em mm cm ${ }^{-3}$. TP - tubete polietileno; PRC - plantio com recipiente orgânico; PRS - plantio sem recipiente orgânico; NS - nível de significância; CV\% - coeficiente de variação; Fcal - F calculado médias de altura (H), diâmetro (D), raiz quadrada do comprimento de raízes laterais (CRL), \% deformação raízes (\% DR), número de raízes (NR), massa seca de raízes (MSR) e massa seca da parte aérea (MSPA).

\section{Conclusões}

Os recipientes fabricados a partir de resíduos sobre certos vegetais da piaçava da Bahia são tecnicamente viáveis para produção de mudas de Eucalyptus camaldulensis, resultando em mudas de qualidade, aptas ao plantio em campo.

Não é necessária a remoção do recipiente biodegradável de fibra de piaçava, para o plantio das mudas em campo.

\section{Agradecimentos}

Casa Familiar Agroflorestal - CFAF da cidade de Nilo Peçanha, Bahia e a Cooperativa das Produtoras e Produtos Rurais da Área de Preservação Ambiental de Pratigi (COOPRAP)

\section{Referências}

Alvarez, C. L. et al. Köppen's climate classification map for Brasil. Meteorologische Zeitschrift, v. 22, n. 6, p. 711-728, 2013. DOI: 10.1127/0941-2948/2013/0507.

Batista, R. O. et al. O efeito da água residuária da suinocultura no desenvolvimento e qualidade de mudas de Eucalyptus urophylla. Ciência Florestal, v. 24, n. 1, p. 127-135, 2014. DOI: 10.5902/1980509813330.

D’Almeida, J. R. M. et al. Tensile mechanical properties, morphological aspects and chemical characterization of piassava (Attalea funifera) fibers. Composites: Part A, v. 37, n. 9, p. 14731479, 2006. DOI: 10.1016/j.compositesa.2005.03.035.

De Conti, A. C. et al. Análise do desenvolvimento e da viabilidade econômica do plantio de mudas de árvores em tubetes biodegradáveis. RETEC: Revista de Tecnologias, v. 5, n. 1, p. 113-121, 2012.

Dias, B. A. S. et al. Análise econômica de dois sistemas de produção de mudas de eucalipto. Floresta e Ambiente, v, 18, n. 2, p. 171-177, 2011. DOI: 10.4322/floram.2011.035.
Dickson, A. et al. Quality appraisal of white spruce and white pine seedling stock in nurseries. The Forestry Chronicle, v. 36, n. 1, p. 10-13, 1960. DOI: $10.5558 / \mathrm{tfc} 36010-1$.

Embrapa Instrumentação Agropecuária. Software Safira. Disponível em: $<$ http://labimagem.cnpdia.embrapa.br/Ferramentas. aspx?ferramenta=4>. Acesso em: 4 maio 2015.

Ferraz, M. V. et al. Produção de mudas de petúnia comum em tubetes biodegradáveis em substituição aos sacos plásticos. Brazilian Journal of Biosystems Engineering, v. 9, n. 1, p. 74-83, 2015. DOI: 10.18011/bioeng2015v9n1p74-83.

Figueiredo, F. A. M. M. A. et al. Condutividade hidráulica de raiz e capacidade fotossintética de mudas clonais de eucalipto com indução de deformações radiculares. Ciência Florestal, v. 24, n. 2, p. $277-$ 287, 2014.DOI: 10.5902/1980509814566.

Freitas, T. A. S. et al. Desempenho radicular de mudas de eucalipto produzidas em diferentes recipientes e substratos. Revista Árvore, v. 29, n. 6, p. 853-861, 2005. DOI: 10.1590/S010067622005000600003.

Freitas, T. A. S. et al. Efeito de deformação e poda das raízes de mudas de eucalipto sobre o crescimento no campo. Floresta, v. 39, n. 2, p. 355-363, 2009. DOI: 10.5380/rf.v39i2.14562.

Gomes, D. R. et al. Lodo de esgoto como substrato para a produção de mudas de Tectona grandis L. Cerne, v. 19, n. 1, p. 123-131, 2013. DOI: 10.1590/S0104-77602013000100015.

Gomes, J. M. et al. Parâmetros morfológicos na avaliação da qualidade de mudas de Eucalyptus grandis. Revista Árvore, v. 26, n. 6, p. 655-664, 2002. DOI: 10.1590/S0100-67622002000600002.

Gomes, M. J.\& Paiva, H. N. Viveiros florestais: propagação sexuada. Viçosa, MG: Ed. UFV, 2011.

IBGE. Produção extração vegetal e da silvicultura: 2013. Rio de Janeiro, v. 28, p.1-69, 2013. Disponível em: <http://www.ibge.gov. br/home/estatistica/economia/pevs/2013/default.shtm>. Acesso em: 4 maio 2015.

Kratz, D. et al. Substratos renováveis na produção de mudas de Eucalyptus benthamii. Ciência Florestal, v. 23, n. 4, p. 607-621, 2013. DOI: $10.5902 / 1980509812345$. 
Kratz, D. \& Wendling, I. Produção de mudas de Eucalyptus dunnii em substratos renováveis. Floresta, v. 43, n. 1, p. 125-136, 2013. DOI: 10.5380/rf.v43il.25989.

National Institutes of Health. ImageJ, processing and analysis in Java. Disponível em: $<$ http://rsb.info.nih.gov/ij/index.html $>$. Acesso em: 4 maio 2015.

Ngulube, M. R. Performance of height-classified Eucalyptus camaldulensis seedlings after one year in the field. New Forests, v. 2, n. 4, p. 275-280, 1988. DOI: 10.1007/BF00027943.

Nogueira, A. C. et al. Adição de maravalha a substratos comerciais na produção de mudas de Eucalyptus grandis Hill ex Maiden. Ambiência: Revista do Setor de Ciências Agrárias e Ambientais, v. 10, n. 2, 2014. DOI:10.5935/ambiencia.2014.02.07.

Oliveira Júnior, O. A. et al. Características morfofisiológicas associadas à qualidade de mudas de Eucalyptus urophylla produzidas em diferentes substratos. Revista Árvore, v. 35, n. 6, p. 1173-1180, 2011. DOI: 10.1590/S0100-67622011000700003.

Petter, F. A. et al. Biochar como condicionador de substrato para a produção de mudas de eucalipto. Revista Caatinga, v. 25, n. 4, p. 44-51, 2012.
R DEVELOPMENT CORE TEAM. R: R version 3.1.3 (smooth sidewalk). Viena: The R Foundation for Statistical Computing, 2015. Disponível em: $<$ http://www.rproject.org> Acesso em: 5. mar. 2015.

Rudek, A. et al. Avaliação da qualidade de mudas de eucalipto pela mensuração da área foliar com o uso de imagens digitais. Enciclopédia Biosfera, v. 9, n. 17, p. 3775-3787, 2013.

Savastano Junior, H. et al. Seleção de resíduos de alguns tipos de fibra vegetal, para reforço de componentes de construção. In: ENCONTRO NACIONAL SOBRE EDIFICAÇÕES E COMUNIDADES SUSTENTÁVEIS, 1., 1997, Canela. Anais...Canela: Antac/UFRGS, 1997. p. 107-112.

Simões, D. \& Silva, M. R. Análise técnica e econômica das etapas de produção de mudas de eucalipto. Cerne, v. 16, n. 3, p. 359-366, 2010. DOI: 10.1590/S0104-77602010000300011.

Silva, D. B. et al. Produção de plântulas de Ingá (Inga vera Willd) cultivadas em tubetes biodegradáveis. Cadernos de Agroecologia, v. 9, n. 4, p. 1-6, 2014.

Wendling, I. \& Dutra, L. F. Produção de mudas de eucalipto por estaquia e mini estaquia. In: Wendling, I.\& Dutra, L. F. Produção de mudas de eucalipto. Colombo: Embrapa Florestas, 2010. p. 50-80. 